\title{
Hereditary punctate keratoderma: Clinical, pathology, treatment and follow-up
}

Article · April 2017

DOI: $10.23736 /$ S0392-0488.16.05281-0

CITATIONS

0

5 authors, including:
READS

14

\section{Giovanni Paolino}

Ospedale di San Raffaele Istituto di Ricovero ... 104 PUBLICATIONS 158 CITATIONS

SEE PROFILE

\section{Michele Donati}

Università Campus Bio-Medico di Roma

25 PUBLICATIONS 20 CITATIONS

SEE PROFILE
Dario Didona

Istituto Dermopatico dell'Immacolata 56 PUBLICATIONS 127 CITATIONS

SEE PROFILE

Some of the authors of this publication are also working on these related projects: 


\section{COPYRIGHT $^{(} 2017$ EDIZIONI MINERVA MEDICA}

LETTERS TO THE EDITOR

TABLE I.-Dermoscopic patterns suggestive for CMMMs. ${ }^{5}$

\begin{tabular}{ll}
\hline Patterns & \multicolumn{1}{c}{ Description } \\
\hline $\begin{array}{l}\text { Blue homogeneous } \\
\text { Vascular (or amelanotic) }\end{array}$ & $\begin{array}{l}\text { Diffuse blue structureless pigmentation } \\
\text { Polymorphic angiectatic blood vessel and/ } \\
\text { or aneurysm of the vessels, in particular } \\
\text { winding vessels and area of polymorphic } \\
\text { and/or horizontally capillary prominence } \\
\text { especially at the border of each lesion }\end{array}$ \\
$\begin{array}{c}\text { Round or ovoid junctional nests of atypical } \\
\text { proliferating melanocytes appearing red-blue, } \\
\text { red brown or blue-gray-colored }\end{array}$ \\
$\begin{array}{c}\text { Other features } \\
\text { Perilesional erythemantary halo and } \\
\text { peripheral grayish } \\
\text { patches }\end{array}$ & $\begin{array}{l}\text { Dilatated capillaries } \\
\text { Presence of melanin in the reticular dermis }\end{array}$ \\
\hline
\end{tabular}

draining lymph node basin due to intralymphatic tumor dissemination, may affect from $2.5 \%$ to $23 \%$ of melanoma patients. 3,4

Our patient had previous excision of an acral lentiginous melanoma characterized by the presence of other three of these factors (high Breslow thickness and mitotic rate, age older than 50 years) and developed these recurrence subtypes in the first years of follow-up.

CMMMs are usually small and un-coalesced, clinically homogenous or non-homogenous, of different colors - from violaceous blue to reddish pink, mimicking common and blue nevi - , hemangioma but also primary cutaneous melanoma. It is possible to observe only one solitary or more frequently multiple lesions. Since clinical guidelines are not always reliable and subsequently these in-transit metastases are often misdiagnosed, dermoscopy could help dermatologists to early detect them, above all in high risk patients. As reported in the literature (Table I), some dermoscopic features such as blue homogeneous, vascular and saccular patterns associated with peripheral grey spots, perilesional erythema or pigmentary halo are strong indicators of CMMMs. ${ }^{5}$

Our patient presented clinically and also dermoscopically heterogeneous CMMMs, showing at the same time all the dermoscopic patterns previously described in the literature. In conclusion, since CMMMs are very difficult to diagnose, it is crucial to know their different dermoscopic features, which could all be found in the same patient - as is our case - in order to allow their excision and to avoid their spread.

\section{Ginevra PERTUSI ${ }^{1}$, Benedetta MIGLINO 2 *, Rossana TIBERIO ${ }^{2}$, Federica VERONESE ${ }^{2}$, Roberto GIORGIONE 2, Massimo GATTONI 1, Enrico COLOMBO 2}

${ }^{1}$ Department of Dermatology, S. Andrea Hospital, Vercelli, Italy; ${ }^{2}$ Dermatology Clinic, University of Eastern Piedmont, Novara, Italy *Corresponding author: Benedetta Miglino, Dermatology Clinic, Corso Mazzini 18, 28100, Novara, Italy. E-mail: bennymiglino@libero.it

\section{References}

1. Bradford PT, Goldstein AM, McMaster ML, Turcker MA. Acral lentiginous melanoma. Incidence and survival patterns in the United States, 1986-2005. Arch Dermatol 2009;145:427-34.

2. Oh TS, Bae EJ, Ro KW, Seo SH, Son SW, Kim IH. Acral Lentiginous Melanoma developing during long-standing atypical melanosis: usefulness of dermoscopy for detection of early acral melanoma. Ann Dermatol 2011;23:400-4.

3. Stucky CC, Gray RJ, Dueck AC, Wasif N, Laman SD, Sekulic A, et al. Risk factor associated with local and in-transit recurrence of cutaneous melanoma. Am J Surg 2010;200:770-5.

4. Clemente-Ruiz de Almiron A, Serrano-Ortega S. Risk Factors for In-Transit Metastasis in Patients With Cutaneous Melanoma. Actas Dermosifiliogr 2011;102;226-29.

5. Bono R, Giampetruzzi AR, Concolino F, Puddu P, Scoppola A, Sera $\mathrm{F}$, et al. Dermoscopic patterns of cutaneous melanoma metastases. Melanoma Res 2004;14:367-73.

Conflicts of interest.-The authors certify that there is no conflict of interest with any financial organization regarding the material discussed in the manuscript.

Article first published online: September 15, 2016. - Manuscript accepted: February 22, 2016. - Manuscript revised: February 17, 2016. - Manuscript received: November 19, 2016.

(Cite this article as: Pertusi G, Miglino B, Tiberio R, Veronese F, Giorgione $\mathrm{R}$, Gattoni M, et al. Different dermoscopic patterns of cutaneous melanoma metastases in the same patient. G Ital Dermatol Venereol 2017;152:321-2. DOI: $10.23736 / \mathrm{S} 0392-0488.16 .05275-5)$

(C) 2016 EDIZIONI MINERVA MEDICA

Online version at http://www.minervamedica.it

Giornale Italiano di Dermatologia e Venereologia 2017 June;152(3):322-3

DOI: $10.23736 / \mathrm{S} 0392-0488.16 .05281-0$

\section{Hereditary punctate keratoderma: clinical, pathology, treatment and follow-up}

\section{Dear Editor,}

First described by Brown in 1971, punctate keratoderma $(\mathrm{PK})^{1}$ is a rare disorder, characterized by keratotic lesions on the palmo-plantar regions. Two types of PK have been described: the idiopathic and the hereditary variant. ${ }^{2}$ The idiopathic PK has been more commonly reported in the literature, often in association with neoplastic and non-neoplastic disorders. ${ }^{2-5}$ Contrariwise, few documented cases of hereditary PK have been reported in the literature supported by clinical and pathological pictures. ${ }^{2}$

A 66-year-old Caucasian man presented to our Institute with yellowish and asymptomatic keratotic papules, which had appeared gradually over the past 9 years on both palms without any involvement of the soles (Figure 1A, B). His 45-year-old daughter also presented small, yellowish/whitish, asymptomatic, keratotic papules on her palms, that had appeared over the last 6 years 

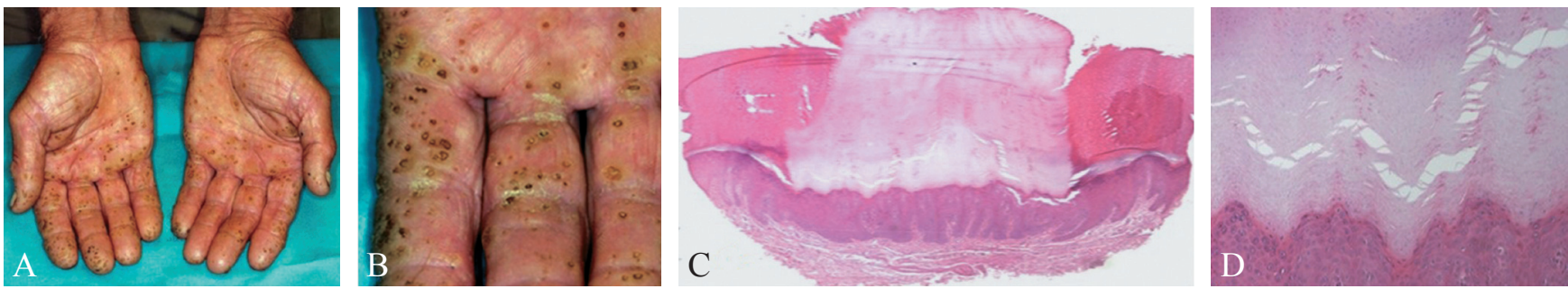

Figure 1.-A) Yellowish keratotic papules on father's palms; B) yellowish keratotic papules of the palms (close view); C) acanthosis, hypergranulosis and orthokeratosis with a distinct thick column of parakeratosis (H\&E 10x); D) detail of the distinct thick column of parakeratosis (H\&E 30x)

(Figure 2A). Clinical examination did not highlight any further alterations and the familial and personal medical history was negative for malignancies, as well as for internal and skin diseases in both patients. A punch biopsy of the palm of each patient was performed. The pathological examination revealed in skin specimens acanthosis, hypergranulosis and orthokeratosis, with a distinct thick column of parakeratosis in the central part of lesions (Figures 1C, D, 2B). Dyskeratosis, vacuolated cells and atypical cells were not observed. Therefore, a final diagnosis of PK was made. The father received acitetrin and an improvement of the lesions was observed. However, the lesions arose again after stopping the treatment. Contrariwise, his daughter refused any therapy. After a follow-up of 8 years, they both continue to perform clinical control in our Department and routine systemic examinations.

Inherited PK is an autosomal dominant disease, usually not associated with internal or malignant disorders. For this reason, inherited PK it has been reported as the benign type of PK. ${ }^{2}$

PK may be mistaken for several diseases, including viral warts, nevoid basal cell carcinoma, pitted keratolysis, arsenical keratosis, and palmoplantar porokeratosis (PP). ${ }^{3}$ However, it is important to highlight that PK and PP are different skin diseases. ${ }^{2,} 5$ Indeed, PK clinically lacks the typical centrifugally expanding circles of PP. In addition, PK lesions do not form plaques. Pathologically, only PP shows, beneath the parakeratotic column, dyskeratosis and vacuolated keratinocytes in the epidermis. Furthermore, it has been reported that (under electron microscopic examination) the epidermis of PK, under the parakeratotic column, does not show

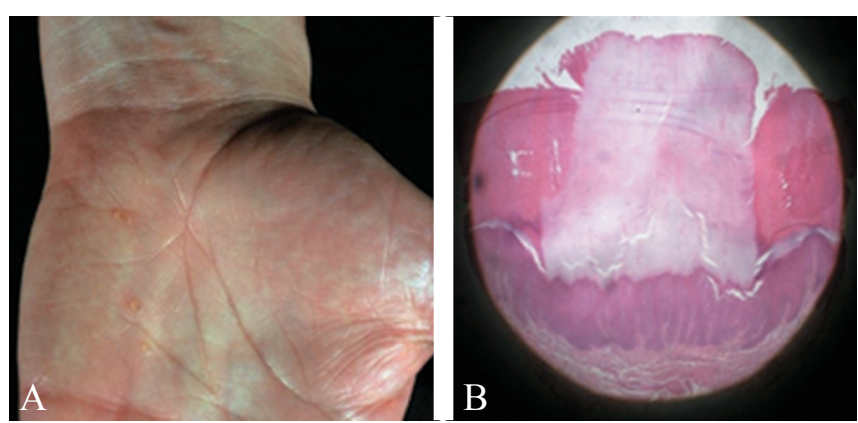

Figure 2.-A) Yellowish keratotic papules on daughter's palms; B acanthosis, hypergranulosis and orthokeratosis with a distinct thick column of parakeratosis (H\&E 10x). dyskeratosis, vacuolar degeneration or exaggerated clumping of tonofilaments, that contrariwise have been highlighted in PP. ${ }^{5}$

In acquired PK, the incidence of malignancies, as well as other internal disease, remains inexplicably high. However, based on the long follow-up (14 years), both patients did not show any internal disorders or malignancies associated to PK.

On the one hand, topical treatments of PK, including urea, salicylic acid, vitamin A, retinoids, and tacalcitol, usually show poor results. $^{2}$ On the other hand, systemic therapy with oral retinoids could lead to a good improvement of lesions. ${ }^{2}$ However, recurrence after stopping therapy is common, ${ }^{2}$ as reported in our case.

Chiara PANETTA ${ }^{1}$, Giovanni PAOLINO ${ }^{1}$, Dario DIDONA ${ }^{2} *$, Michele DONATI ${ }^{1}$, Pietro DONATI ${ }^{1}$

${ }^{1}$ Dermatopathological Laboratory Institute, "San Gallicano Institute of Rome", Rome, Italy; ${ }^{2}$ First Unit of Dermatology, Istituto Dermopatico dell'Immacolata-IRCCS, Rome, Italy

*Corresponding author: Dario Didona, Via dei Monti di Creta 104, 00167 Rome, Italy. E-mail: didona.dermatology@gmail.com

\section{References}

1. Brown FC. Punctate keratoderma. Arch Dermatol 1971;104:682-3.

2. Adegbayibi A, Doherty V, Biswas A. Multiple Keratotic Papules on the Palm and Fingers. Spiny keratoderma. Am J Dermatopathol 2015;37:620-58

3. Urbani CE, Moneghini L. Palmar spiny keratoderma associated with type IV hyperli-poproteinemia. J Eur Acad Dermatol Venereol 1998;10:262-6.

4. Bianchi L, Orlandi A, Iraci S, Spagnoli LG, Nini G. Punctate porokeratotic kerato-derma--its occurrence with internal neoplasia. Clin Exp Dermatol 1994;19:139-41.

5. Osman Y, Daly TJ, Don PC. Spiny keratoderma of the palms and soles. J Am Acad Dermatol 1992;26(5 Pt 2):879-81.

Conflicts of interest.-The authors certify that there is no conflict of interest with any financial organization regarding the material discussed in the manuscript.

Manuscript accepted: February 22, 2016. - Manuscript revised: February 17, 2016. - Manuscript received: November 22, 2015.

(Cite this article as: Panetta C, Paolino G, Didona D, Donati M, Donati P. Hereditary punctate keratoderma: clinical, pathology, treatment and follow-up. G Ital Dermatol Venereol 2017;152:322-3. DOI: 10.23736/S03920488.16.05281-0) 